\title{
Interpretació en Llengua de Signes Catalana d'una Cançó amb Alumnes De P5
}

\section{Estel Muñoz Manero}

\section{Introducció}

Aquesta experiència didàctica pretén apropar als infants al món de les persones sordes i introduir la llengua de signes, llengua que usen part dels membres de la comunitat sorda, mitjançant la interpretació d'una cançó en Llengua de Signes Catalana (LSC).

S'ha dut a terme amb infants de $\mathrm{P} 5$, i la idea va sorgir arrel d'una experiència prèvia que van fer els i les alumnes de primària d'una escola galega ${ }^{1}$. El plantejament va ser llavors, fer el mateix amb infants més petits, en aquest cas de 5 anys, i potenciar així l'aprenentatge primerenc, aprofitant les condicions de plasticitat neuronal que tenen durant els primers anys.

També es pretén usar la llengua de signes com a estratègia inclusiva, per tal que els alumnes coneguin una realitat diferent a la seva, així com la llengua de les persones sordes i les seves característiques. Per una altra banda aquesta ha estat una activitat que ha permès adaptar-se als diferents ritmes de treball dels infants i respectar les seves característiques.

Els objectius concrets que perseguia aquesta experiència eren els següents:

- Conèixer la llengua de signes i saber com funciona.

- Conèixer l'existència de les persones sordes, i algunes de les seves característiques.

- Treballar conceptes musicals com ara el ritme i la pulsació.

- Desenvolupar la motricitat fina i gruixuda.

- Treballar l'orientació espaial.

- $\quad$ Entendre com funciona la interpretació.

- Observar, aprendre i interpretar un cançó signada.

- Participar de forma activa en el projecte. 
- Conèixer com s'elaboren els videoclips.

- Apreciar i valorar el treball en equip i la importància de cadascú dins del grup.

- Valorar els aprenentatges adquirits.

- Desenvolupar una autoestima i una autoimatge positives valorant l'esforç realitzat

- Desenvolupar habilitats de comunicació, expressió, comprensió i representació per mitjà dels llenguatges corporal, musical i verbal.

- Aprendre a gaudir de l'aprenentatge, pensar i crear, qüestionar-se les coses, fer-les ben fetes, plantejar i acceptar la crítica i fer créixer el coneixement d'una manera cada vegada més estructurada.

\section{Metodologia emprada}

La metodologia emprada parteix de la concepció constructivista, i es basa, entre d'altres, en la teoria de l'aprenentatge significatiu de David P. Ausubel.

Per aprenentatge significatiu s'entén aquell en el qual la nova informació es relaciona de manera substantiva i no arbitrària, amb els coneixements que l'alumne ja posseeix produint-se una transformació, un canvi, tant en el contingut que s'aprèn i s'assimila com en el que l'estudiant ja sabia. Suposa vincular la nova informació amb conceptes ja existents en l'estructura cognitiva (Martin i Solé, 2005). Per tant, crearà els seus propis aprenentatges a partir de les eines que el/la mestre/a li proporciona, quelcom implica també, que l'alumne construeixi de manera activa el seu aprenentatge, modificant allò que ja sabia amb els nous coneixements.

A la pràctica, en aquesta experiència, a les primeres sessions, activarem i avaluarem els coneixements previs dels infants amb diàlegs i preguntes per tal de saber què en saben ells i elles sobre la llengua de signes $\mathrm{i}$ les persones sordes. Poc a poc introduirem la nova informació relacionant-la amb el què ja coneixen.

Durant l'aprenentatge dels signes de la cançó, associarem els signes a la paraula, i utilitzarem analogies i comparacions per a relacionar les configuracions de signes més complicades amb objectes, formes o conceptes que ja coneixen.

El constructivisme proposa un procés d'ensenyament-aprenentatge dinàmic, actiu, participatiu i interactiu per part dels alumnes, de manera que el coneixement sigui una construcció per part del discent. Per aquest motiu, aquesta seqüència didàctica es considera vivencial, experimental i observacional. 


\section{Atenció a la diversitat}

A l'aula, a part de la diversitat de nens i nenes, ritmes d'aprenentatge i característiques de cada infant, hi havia el cas d'una alumna amb necessitats educatives especials. Presenta dificultats en la psicomotricitat fina i gruixuda, en la parla i en la vista de la part dreta del cos. També és molt possible que tingui afectat el QI però encara és massa aviat per a determinar-ho.

No es van canviar els objectius ni en suprimírem cap, ja que és capaç d'arribar a tots. El que es va fer va ser adaptar el ritme de cada sessió que treballem amb ella, al seu, i controlar la seva evolució, de la mateixa manera que es va fer amb els altres, però amb més supervisió.

\section{Avaluació}

Mitjançant l'observació, i gràcies a treballar en petit grup, a cada sessió es va anar avaluant la progressió infants i quan calia es rectificaven els signes, les posicions, etc. Podem dir llavors que l'avaluació ha estat continua i individualitzada.

El vídeo, que va ser el resultat final de l'experiència, també ha servit "prova" física d'avaluació final, tot i que el més important no és que els nens i nenes signin la cançó a la perfecció, ja que cadascú té un nivell maduratiu motriu diferent, i la llengua de signes, igual que la llengua oral, segueix un procés d'aprenentatge, i de la mateixa manera que un nen o nena de cinc anys no parla la llengua oral a la perfecció, a la llengua de signes passa el mateix. Per tant el que avaluarem serà l'evolució que han tingut, la participació i la motivació que han mostrat, i el resultat global en general.

\section{Descripció de les activitats}

\section{Activitat 1: presentació del projecte}

Seurem tots i totes davant la pantalla del projector. Sense avançar als nens i nenes què veuran, visualitzarem el vídeo on apareixen nens i nenes d'una escola de Galícia interpretant una cançó en llengua de signes. Quan acabi, encetarem un diàleg fentlos preguntes com ara: què feien aquests nens i nenes?, per què ho feien?, per a què? Què creieu que volen dir aquests moviments de mans?, etc. Poc a poc, a mida que vagin contestant les preguntes, i valorant els coneixements previs que tinguin sobre el tema, anirem introduint-los la nova informació sobre la llengua de signes, les persones sordes, el que fan realment els nens del vídeo (interpretar), etc.

Al acabar el diàleg, quan ja tinguin ben clar què estaven fent els alumnes del vídeo, perquè, com ho han fet, etc., els proposarem fer-ho nosaltres dient-los: què us semblaria que nosaltres interpretéssim en llengua de signes una cançó que ens agradés per a que les persones sordes la puguin entendre? Us agradaria fer-ho? 
Quan decidim fer-ho, els explicarem que buscarem cançons i que escolliran la que més els agradi, el proper dia.

\section{Escollim la cançó}

Recordarem als infants el què vam fer la sessió anterior i què vam decidir. Els presentarem tres cançons que hem seleccionat. Totes elles tindran valor per les característiques musicals però també pel tipus de missatge que transmeten.

Els alumnes escoltaran les cançons dues vegades, una primera vegada les tres seguides, i els direm que ho tornarem a escoltar i que decideixin quina volen escollir, la número 1 , la 2 o la 3.

Per tal que no s'influeixin en el vot, farem una votació en paper. Cadascú i cadascuna escriurà en un paper el número de la cançó que més li ha agradat. Quan tothom hagi acabat, farem el recompte en veu alta, per tal que siguin conscients del valor del seu vot, i anirem apuntant a la pissarra, a cada cançó, tants palets, o senyals com vots rebi. Al final farem el recompte i anunciarem quina ha estat la cançó guanyadora.

\section{Treballem la cançó}

Recordarem què vam fer el dia anterior, les decisions preses i la cançó que va sortir escollida. Prepararem l'aula per a treballar la cançó enretirant les taules i les cadires i creant un espai ampli per a cabre-hi tots i totes en rotllana àmpliament.

Posarem una primera vegada la cançó i deixarem que els alumnes l'escoltin i s'expressin lliurement per l'aula.

Tronarem a posar la cançó i aquesta vegada, en rotllana, reproduirem, amb diferents parts del cos, la pulsació de la cançó. Començarem amb els peus; després picant les mans a les cuixes, al cap, a la panxa, etc.; picant amb un dit a la mà, caminant tots i totes en un sentin continuant la rotllana, etc. a continuació farem el mateix amb el ritme.

Quan acabem, seurem tots i totes a terra i parlarem sobre les parts de la cançó: l'estrofa i la tornada. Preguntarem primer si saben quines són les parts de la cançó, com es diu la frase que es repeteix sempre, etc., per tal d'esbrinar els coneixements previs dels infants. Podem ajudar-nos de la música i tornar a reproduir la cançó en les parts que ens interessi. Els explicarem com es diu cada part de la cançó i per quina part començarem a treballar nosaltres (la tornada).

Recordarem què feien els nens i nenes del vídeo de Galícia i els explicarem en què consisteix la interpretació, on cada paraula va associada a un signe. Podem ajudarnos d'exemples de signes i paraules per tal que entenguin el concepte. Al acabar els preguntarem per a motivar-los, "voleu que ho fem?". Dempeus i en rotllana, signarem 
poc a poc la primera frase, i explicarem què vol dir cada signe. Ho anirem repetint varies vegades tots $i$ totes alhora.

\section{L'assaig}

Aquesta activitat es desenvoluparà durant diferents dies i horaris (vegeu temporització).

En grups reduïts d'alumnes (3-4), alhora que la resta fan classe normal, assajarem la tornada de la cançó. Ens ubicarem a un espai diferent, buscarem una aula buida on puguem assajar tranquil.lament. Les sessions d'assaig amb cada grup seran de màxim 10 minuts.

Recordarem els signes que vam aprendre i els farem, primer sense música, marcant la pulsació. Començarem fent una pulsació més lenta que la de la cançó, i poc a poc, a mida que dominin els signes, anirem augmentant la velocitat fins arribar a la mateixa que la de la peça musical. Després assajarem amb la música. Si estem a l'aula, podem usar l'ordinador, sinó, podem reproduir la cançó al mòbil o algun altre aparell de què disposem.

A les primeres sessions d'assaig ens hem d'assegurar que dominen bé els signes, a mida que ho facin, anirem introduint-ne més, fins a fer tota la tornada.

Quan ja tinguin ben assolida la tornada, introduirem la primera estrofa, i després la segona.

Farem, de tant en tant, assajos tots i totes junts, a l'aula. Podem aprofitar al final de les sessions d'assaig, quan acabem de fer-ho amb tels grups reduïts, abans de marxar a casa, interpretar junts la cançó.

Els dos dies abans de la representació al festival, farem assaig general, imaginant que estem a l'espai real (l'escenari), ubicant-nos en la posició correcta, i assajant tota l'escenografia.

\section{Gravem el videoclip}

Aquesta activitat es realitzarà en dos dies, durant els quals, mentre els alumnes fan classe normal, gravarem el vídeo amb el nens i nenes, individualment, per grups, i en gran grup, depenent de les diferents seqüències.

Prèviament haurem elaborat un guió amb l'ordre de sortida de cada infant, i allò que ha d'interpretar. També buscarem l'espai adequat per a fer cada enregistrament i el prepararem. Per a totes les preses individuals i de petit grup utilitzarem un fons blanc, per a la de gran grup, ens adequarem a l'espai que tinguem per a que càpiguen bé tots els nens i nenes.

Els alumnes aniran vestits amb diferents samarretes de color llis i viu. 
Enregistrarem el vídeo seguint el guió elaborat. Posteriorment, l'editarem i el muntarem.

Quan ja estigui muntat, els hi ensenyarem als infants i els explicarem com ho hem fet, per tal que entenguin que de molts vídeos curts se'n fa un de llarg, que es munta, es mira el temps, etc.

\section{Valoració de la intervenció educativa.}

La intenció era que amb aquest treball, els nens i nenes coneguessin part de la realitat i la cultura de les persones sordes; descobrissin una llengua visual completament diferent a la que parlen; desenvolupessin la motricitat fina; i assumissin un repte que, de primeres, era difícil, i aprenguessin a treballar, a concentrar-se, a esforçar-se per un objectiu, i quan l'aconseguissin, veiessin que són capaços de fer coses que desconeixien, que en un primer moment potser els semblaven impossibles i per a la que no es veien capaços i capaces; alhora, amb tot aquest treball, desenvolupessin una autoestima i una autoimatge positives, i que això els donés seguretat.

Assolir aquests tipus d'aprenentatges, és molt valuós, perquè els permetrà aprendre'n de nous, i el que és més important, desenvolupar-se com a persona de manera segura i positiva.

Tot i ser un tema desconegut per als infants, des del principi vam intentar relacionarho amb els coneixements previs que tenien, seguint així una visió més constructivista. És per això, que sobretot les primeres dues sessions, recolzades amb el vídeo de l'experiència galega, les vam dedicar a parlar del què sabien, i vaig anar relacionantho amb la nova informació.

Durant l'aprenentatge dels signes, la metodologia que vam emprar va ser la observació de la producció del signe que jo feia, i la repetició per part dels i les alumnes. Aquest fet es produïa d'una manera gairebé natural, i jo tan sols havia d'anar polint petits detalls i modificant posicions de dits i mans que no estaven del tot ben colllocades. El que sí és cert, és que, per als signes més difícils o més estranys, vaig anar associant la forma que tenien amb coses que ells i elles podien conèixer, per exemple: el signe INTENTAR, els deia que havien de fer com si es dibuixessin unes antenes al cap.

L'organització va ser un fet rellevant i de molta importància durant tota l'experiència. Vàrem presentar la cançó per parts, començant per la tornada, que era el que més es repetia, i quan ja tenien ben assimilats els signes, vam anar introduint la primera estrofa, i després la segona.

Treballàvem amb grups el més reduïts possibles, per poder donar una atenció més individual i poder observar millor l'evolució de cada infant. 
Els assajos es duien a terme a les hores de classe, per tant, mentre la mestra feia la classe que tocava amb tots els alumnes, jo m'anava emportant grups reduïts de nens i nenes a l'aula del costat, i assajàvem una estona, i quan acabàvem, canviava el grup. Així fins que tots i totes assajaven. Vaig crear una llista on apuntava les vegades que anava assajant cadascú, ja que no sempre m'emportava el mateix grup de nens i nenes, d'aquesta manera, si hi havia dies que no donava temps a assajar tothom, sabia qui havia d'agafar al dia següent, i tothom assajava el mateix.

Les primeres setmanes, aprofitava sovint les estones d'esbarjo per assajar. Ho feia en grups petits i sempre preguntava si volien venir. Si hi havia algú que estava engrescat/da jugant i no volia venir, ho respectava, ja que no volia que fos una cosa forçada o imposada per als alumnes. Però aquesta situació no es va donar gairebé mai, perquè cada dia que passava estaven més i més motivats i motivades, i s'ho prenien amb molta il.lusió.

Els assajos que fèiem a hores d'esbarjo, solien ser més distesos. Els fèiem a l'aula i sempre posava l'ordinador amb la cançó. Deixava que ballessin i que s'expressessin més lliurement una estona, i després, assajàvem la cançó amb signes, de vegades sencera, de vegades a trossos, en funció de com estaven ells i elles. La qüestió era fer-ho el més distés possible, i si algú es cansava o de sobte no tenia ganes d'assajar, podia fer una altra cosa, però això rarament va passar.

La quantitat de nens i nenes per grup al principi era més o menys la mateixa (3-4 nens i nenes). A mesura que vàrem anar avançant, feia grups més grans amb nens $i$ nenes que ho portaven millor i en posava un que li costava més, per exemple, feia grups de 6 on 2 ho portaven molt bé, 3 ho portaven bé, i 1 que li costava una mica més. D'aquesta manera fomentava l'aprenentatge entre iguals amb els que ho portaven bé, i també podia dedicar-li més atenció a aquell o aquella que ho necessitava.

També, de vegades, amb els nens i nenes que veia que els costava més, treballava més amb ells posant-los a grups molt reduïts, de 2-3 persones.

Les sessions d'assaig eren curtes, de 10 min. Màxim. Com que gairebé vam assajar cada dia, no volia que se'ls fes repetitiu o pesat, i intentava estar el temps just en cada grup. Els assajos havien de ser dinàmics, intensos, clars i curts, i amb la informació justa.

Al decidir-nos a fer aquest projecte, vam establir, dins la programació de l'aula, els dies que podíem dedicar a assajar, que eren els dies en què tot el grup classe estava junt i que, per la matèria que tocava donar, ens permetia assajar en grup petit alhora que la resta d'alumnes feia classe.

Les tres primeres sessions van ser de gran grup, tots i totes junts. La resta, eren en petit grup, i de tant en tant, al final de cada sessió, fèiem un assaig en gran grup.

Una de les coses que més em va sorprendre va ser el cas d'una nena amb NEE que teníem a l'aula. Quan ens vam decidir a fer aquest projecte, semblava que les 
expectatives eren massa altes per a ella, perquè té dificultats en la motricitat i en la parla, capacitats clau en aquesta experiència. Jo estava una mica inquieta per saber com s'ho prendria, no volia que es frustrés al veure que potser no podia fer el que els seus companys i companyes feien, però la veritat es que em va donar una lliçó que no oblidaré. El seu caràcter lluitador va fer que es prengués aquesta experiència com si fos un repte. Feia els signes menys clars que la resta, sí, però els feia. Li costava signar a la mateixa velocitat que la cançó, sí, però l'acabava signant. No es donava mai per vençuda, no es frustrava i seguia endavant sense preguntar a ningú ni reclamar atenció. Quan anàvem assajar, estava contenta, reia i cridava contenta mentre entràvem a la sala, vaig notar un canvi en l'expressió de les emocions i els sentiment en ella durant el temps que vam fer aquesta experiència. Estava molt motivada, contenta en els assajos, atenta, implicada. He vist un canvi molt gran en ella des que vaig començar les pràctiques fins ara. No només en la relació amb mi sinó amb els altres també. Al principi, a classe es relacionava molt amb una nena, i la prenia de referent per a tot. Poc a poc s'ha anat obrin i cada vegada es relaciona amb més companys i companyes. Potser compartir aquesta experiència l'ha ajudat.

La valoració que faig de tota aquesta vivència, és molt positiva, tant del resultat obtingut com de tot el procés i l'evolució que han seguit els i les alumnes.

Abans de començar amb la seqüència didàctica, estava il.lusionada, i sabia que seria un projecte molt maco i enriquidor, no només per als alumnes, sinó per a mi també. Però la realitat ha superat totes les expectatives que en un principi em vaig crear, començant per com han treballat els nens i nenes, com s'han esforçat, la implicació i l'interès que han tingut durant tot el procés. No han perdut mai la motivació, i quant més sabien, més volien saber, sovint em preguntaven els signes de paraules noves, que no tenien a veure amb la cançó, o els veia jugant al pati i fent la cançó entre ells, els uns als altres.

Han aprés molt més ràpid del que jo em pensava. Creia que els costaria més fer els signes, i recordar-se de tots, però no va ser així, la veritat és que tot el procés va ser bastant natural, molt fluït, i gairebé sense adornar-nos-en vam arribar al dia de la representació al festival de Nadal. Aquests van ser un dels dies que no oblidaré, era el premi a tot un esforç, la prova definitiva, l'objectiu que ens havíem marcat i al què havíem arribat tots i totes junts.

El dia de la representació davant de tots els alumnes de l'escola, va ser el previ, la posada en escena, i ens va servir d'assaig final per al dia de l'estrena. Vam practicar com colllocar-nos al escenari, les entrades i les sortides, els temps, etc., i els nens i nenes es van familiaritzar amb l'espai. Tret d'alguns errors meus de col-locació dels infants, tot va sortir molt bé. Però el dia de la representació davant dels pares, es van superar, tot va sortir perfecte.

Al principi estava nerviosa, no sabia si el fet que hi haguessin els pares i mares a l'escenari els distrauria o els posaria nerviosos/es. Vam entrar, ens vam collocar i va començar a sonar la música. Va haver uns quants que es van posar nerviosos mentre esperaven a que comencés la lletra, i s'entretenien amb els del costat, o es quedaven 
fixament mirant al públic, però quan va començar la cançó, va ser màgic, tothom es va centrar en el que havia de fer, i em seguien atents i atentes amb la mirada, concentrats en els signes, les paraules, els ritmes i tota la posada en escena. Va ser un èxit total, aclaparador, un moment que no oblidaré mai.

\section{Propostes de millora}

Aquesta seqüència didàctica se surt una mica del que és habitual, perquè l'activitat principal, que és aprendre la cançó en llengua de signes, no dura només una sessió, sinó que són varies. Això em va donar l'oportunitat d'anar modificant i millorant la meva intervenció a mida que passaven els dies. A cada sessió m'autoavaluava, i si sorgia alguna dificultat, pensava quina era la millor manera de reconduir-ho.

La principal proposta de millora és poder tenir més temps per a desenvolupar-la ja que s'haguessin pogut treballar millor les activitats introductòries, i sobre tot, més temps per a gravar el vídeo i per després fer una sessió en la que els alumnes haguessin participat una mica en el muntatge i tot el procés.

Aquest projecte ha donat molt de sí, i més que podria haver donat, per això hem decidit continuar. Tot i que ja no estic fent pràctiques a l'escola, hem pensat que tot el treball que hem fet no es pot quedar aquí, i hem decidit escriure-li una carta al Macaco, l'autor de la cançó. La intenció és mostrar-li el treball que hem fet i demanar-li permís per a usar la seva cançó, per si ho publiquem a la xarxa, i, qui sap, potser sorgeix alguna nova proposta.

\section{Notes}

${ }^{1}$ Colegio Atlántida, de Vigo. La mestra : Beatriz Durán.

http://www.lavozdegalicia.es/noticia/vigo/2013/11/14/ninos-vigo-arrasan-redcancion-lengua-signos/00031384426703556267828.htm

\section{Nota biogràfica}

Estel Muñoz Manero. Universitat Rovira i Virgili. Grau d'Educació Infantil 